\title{
Getting Started with Taiji: Investigating Students Expectations and Teachers Appraisals of Taiji Beginners Courses
}

\author{
Marko Nedeljkovic, ${ }^{1}$ Christina Bürgler, ${ }^{1}$ Petra H. Wirtz, ${ }^{2}$ Roland Seiler, ${ }^{3}$ \\ Konrad M. Streitberger, ${ }^{4}$ and Brigitte Ausfeld-Hafter ${ }^{1}$ \\ ${ }^{1}$ Institute of Complementary Medicine KIKOM, University of Bern, Imhoof-Pavillon, Inselspital, 3010 Bern, Switzerland \\ ${ }^{2}$ Department of Psychology, University of Bern, Biological and Health Psychology, Alpeneggstraße 22, 3012 Bern, Switzerland \\ ${ }^{3}$ Institute of Sport Science, University of Bern, Alpeneggstraße 22, 3012 Bern, Switzerland \\ ${ }^{4}$ Department of Anesthesiology and Pain Therapy, University Hospital Bern, Inselspital, 3010 Bern, Switzerland
}

Correspondence should be addressed to Marko Nedeljkovic, marko.nedeljkovic@kikom.unibe.ch

Received 9 August 2012; Accepted 10 October 2012

Academic Editor: Hans-Christian Deter

Copyright (C) 2012 Marko Nedeljkovic et al. This is an open access article distributed under the Creative Commons Attribution License, which permits unrestricted use, distribution, and reproduction in any medium, provided the original work is properly cited.

In recent years, Taiji has been frequently investigated and considered as a stress management intervention. Although health care providers' appraisals and consumers' expectations are regarded as essential for treatment outcome, little attention has been drawn to this issue in Taiji research. In our study we have conducted two surveys to explore beginners' $(n=74)$ expectations and teachers' $(n=136)$ appraisals of their Taiji courses in general as well as more particularly related to stress management. Qualitative data analysis revealed that beginners mainly expected to learn a new method that is applicable in their daily life to foster peace of mind and to enhance their stress management. Congruently moderate-to-high improvements in stress management have also been found in quantitative analysis, whereby a lower educational level predicted higher expectations $(P=0.016)$. Taiji-teachers stated body- and mind-related benefits most frequently and appraised moderate-to-high improvements in stress management. Higher appraisals were predicted by a shorter teaching experience $(P=0.024)$. Our results inform about beginners' expectations and teachers' appraisals related to a Taiji-beginners course and highlight the role of educational background and teaching experience in shaping stress-management-related beginners' expectations and teachers' appraisals.

\section{Introduction}

In the recent past, the interest in mind-body practices for health promotion and stress management has considerably increased in the general and clinical population as well as in the scientific community [1-5]. In particular, Taiji (or T'ai Chi, T'ai Chi Chuan, Taijiquan), a mind-body practice originating from China, became more popular in western countries in the last decades [6-8]. Taiji is defined by Wayne and Kaptchuk [6] as "an exercise based on slow intentional movements, often coordinated with breathing and imagery, which aims to strengthen and relax the physical body- and mind, enhance the natural flow of what the Chinese call $q i$ (..., life energy), and improve health, personal development, and self-defense" (page 96). In fact, numerous clinical trials and systematic reviews examined the effectiveness of Taiji for various health conditions, underlining its preventive and therapeutic value, for example, for fall prevention [9-12], for treatment of chronic diseases [9, 13-16], and for improvement of mental health $[9,10,17]$, where a particularly growing body of evidence is supporting the beneficial effects of Taiji practice on stress management [17-22]. However, hitherto only a few studies have been published explicitly investigating the underlying modes of action of Taiji $[6,23$, 24]. Taiji is regarded as a complex intervention, comprising multiple components of which each may have independent and synergistic therapeutic value. Two of these components are students' expectations and teachers' attitudes [6].

As shown in previous research, treatment expectations of health care consumers may influence treatment outcome; in 
particular higher treatment expectations have been repeatedly found to be associated with better treatment results [2529]. The impact of health care practitioners' expectations on treatment results has also been documented [30-32] as well as the crucial importance of the match of treatment-related appraisals and expectations for an outcome enhancing working alliance [33-36].

Even though the above-mentioned findings underline the relevance of expectancies and appraisals on treatment results, to date studies exploring this issue in the field of Taiji and other mind-body practices are scarce. We have found an early Taiji study, where the enhancement of mood after Taiji practice has been partially explained by a higher expectation of a positive outcome (i.e., mood enhancement) in the Taiji group [37]. Although the need for further research into the role of participants' motivation in stress management practices such as Taiji has been highlighted [37], only one qualitative study assessed treatment-related expectations of Qigong beginners [38]. The findings of this study suggest that Qigong beginners with no further specified health status mainly expect improvement of their health condition and relaxation as well as professionalism, provision of information, and empathy from the teachers [38]. To the best of our knowledge, beginners' expectations and teachers' appraisals regarding the benefits of their Taiji courses have not yet been investigated.

Based on the relevance of treatment-related expectations and appraisals for treatment outcome, an increased awareness and knowledge about beginners' expectations and teachers' appraisals of their Taiji-beginners courses may have an impact on treatment outcomes in Taiji interventions. Therefore, the aim of our present study was to explore beginners' expectations and teachers' appraisals of their Taijibeginners courses.

\section{Methods}

2.1. Study Design. We have conducted two surveys, one among Taiji-beginners in the area of Bern and one with Taiji teachers in the German speaking area of Switzerland including the Bern area. The survey of Taiji-beginners was nested within a trial examining psychobiological effects of Taiji on psychosocial stress reactivity [22] and was formally approved by the ethics committee of the Canton of Bern, Switzerland. For the survey of the Taiji teachers, no approval of the ethics committee was required. However, participants' information about the study and the voluntary nature of survey participation, and data protection were handled alike.

2.2. Selection of Subjects. In the first survey, healthy Taijibeginners were recruited through announcements on pin boards and on the websites of the University of Bern and the University Hospital in Bern. Eligible participants had to be between 18 and 50 years old and fluent in German. Exclusion criteria are reported elsewhere in detail [22]. All participants who completed baseline examination were included in this study.
For the second survey, we identified electronically registered Taiji teachers in the German-speaking part of Switzerland by conducting an Internet search in November 2010 using the Google search engine. All of them were invited to participate in an online survey by e-mail. Participants had to be fluent in German and actively engaged as Taiji teachers.

2.3. Data Collection. Both study groups participated in an online survey. After assessing sociodemographic data (for all participants: gender, age, and occupation status; for Taiji-beginners only: education level; for Taiji teachers only: years of Taiji practice experience and years of Taiji-teaching experience) the first question asked to Taiji-beginners aimed to assess their general expectations and was "What are your expectations towards the upcoming Taiji course (= two lessons per week during 3 months)?" Comparably, the Taiji teachers were asked to answer the open question "Which benefits can a newbie expect from a Taiji-beginners course (= two lessons per week during 3 months)?" also by writing down their narrative responses.

To assess beginners' expectations and teachers' appraisals related to changes in stress management in response to regular Taiji practice, all study participants were additionally asked to rate 12 statements expressing Taiji-induced changes in stress coping (6 items) and resource activation ( 6 items), by indicating the degree of their agreement on a 6-point Likert scale ranging from 1 (strongly disagree) to 6 (strongly agree). To avoid priming effects, these items were presented on a new screen page. The full self-developed questionnaire is shown in the Appendix. We defined the sum of all rating scores as an index representing expected or appraised changes in overall stress management induced by regular Taiji practice. This stress management index with a theoretical score range from 12 to 72 has a high internal consistency in Taiji-beginners (Cronbach's $\alpha=0.89$ ), as well as in Taiji teachers (Cronbach's $\alpha=0.94$ ). Construct validity was estimated by pooling data of both study groups and calculating a principal component factor analysis across all 12 items. An analysis of the eigenvalues using scree test [39] resulted in a one general factor solution (eigenvalue $=6.5$ ) with $54.4 \%$ explanation of variance. The item loadings on the general factor ranged from 0.45 to 0.83 .

2.4. Data Analysis. Data analysis was conducted by using SPSS (version 18) statistical software package for Macintosh (IBM SPSS Statistics. Somers, NY, USA). Sociodemographic characteristics of Taiji-beginners and Taiji teachers were analyzed by using descriptive statistics. Unless indicated, all results are presented as mean \pm standard deviation (SD).

Narrative questionnaire data were systematically prepared and analyzed by using a qualitative and quantitative approach [40]. In the qualitative approach, each analytical step has been conducted independently by two authors (MN and CB). After each step, results were compared and differences were discussed until consensus was found. In a first step, each narrative response was screened to detect and mark all analytical units (e.g., beginners' expectations, resp., teachers' perceived benefits). In a second 
step, those analytical units lacking in terminological clarity were explicitly stated. Afterwards, all analytical units were reduced to short paraphrases, comprehensible independent from its originally embedded context. In a next step, we conducted a content analysis of about $50 \%$ of all analytical units and inductively generated thematic categories. The suitability of these categories was tested by classifying the remaining $50 \%$ of all analytical units. After amending the initially defined categories, we reclassified all analytical units. Finally, we thematically captured the final categories into main categories. Both the main and the subcategories were quantitatively described by indicating the frequency of mentions in absolute and percentage values.

In explorative data analysis, we compared beginners' general expectations with teachers' general appraisals related to Taiji-beginners courses by examining group differences of frequency values in each main category using $\chi^{2}$ tests.

In the quantitative approach, we conducted explorative comparisons of stress-management-related to beginners' expectations and teachers' appraisals using a $t$-test for independent samples. Prior to $t$-test calculation, normal distribution of data and homogeneity of variance were verified by the Kolmogorov-Smirnov test and the Levene test. All analyses were two tailed, with the level of significance set at $P \leq 0.05$ and the level of borderline significance set at $P \leq 0.10$.

For Taiji-beginners, we calculated a hierarchical linear regression analysis to examine the predictive value of the independent variables "age," "gender," and "education level" on the expected changes in overall stress-managementrelated to regular Taiji practice (dependent variable). Similarly, we computed a hierarchical linear regression analysis in the group of Taiji teachers to investigate the potential role of the variables "age," "gender," and "teaching experience" as independent predictors of their appraised changes in Taijibeginners' overall stress management due to regular Taiji practice (dependent variable).

\section{Results}

3.1. Group Characteristics. Of the 112 initially registered applicants for a Taiji-beginners course, 74 subjects completed baseline examination and met the inclusion but none of the exclusion criteria. There was no missing data in this group.

Of the 355 invited Taiji teachers, 24 had no valid e-mail address and could not have been reached otherwise, 19 were offering Qigong but no Taiji classes, 10 were not teaching anymore, and 10 were registered twice. Of the remaining 292 potentially eligible Taiji teachers, 136 (47\%) completed the survey. Stress-management-related appraisals were missing from three Taiji teachers. An overview of sociodemographic characteristics of both study groups is presented in Table 1 .

\subsection{Beginners' Expectations towards Their Taiji Course}

3.2.1. Qualitative Analyses. Analyzing Taiji-beginners' answers on the first question assessing course expectations in general, a total of 299 expectations (mean $4.04 \pm 1.84$ ) were stated. As shown in Figure 1, beginners mentioned dailylife-related expectations (comprising 20\% of all expectations mentioned) approximately as frequently as knowledge related (19\%), mind-related (17\%), and mind-body-related expectations (17\%), while body-related (15\%) and process and context-related expectations (11\%) were mentioned less frequently.

With respect to frequencies of expectations as represented in the subcategories, "get to know Taiji in general" was mentioned by $57 \%$ of all Taiji-beginners followed by "improvement of stress management" (41\%) and "increase of internal balance and peace of mind" (32\%). $27 \%$ of all beginners also expected "transferability of course content into daily life" and an "increase of body awareness". The expectation "increase of relaxation" was mentioned by $26 \%$ of the course applicants. Complete results are shown in Table 2.

3.2.2. Quantitative Analyses. From regular Taiji practice (i.e., one hour twice a week during three months) beginners expected a moderate-to-high improvement of their stress management (mean 53.50 \pm 9.56; range $=12$ to 72 ) . Regression analysis revealed that a lower education level significantly predicted higher improvements in the successful management of stress $(\beta=-0.29 ; P=0.016)$, whereas age and gender did not (see Table 3 ). The whole model explained $9.1 \%$ of total variance in beginners expected stressmanagement-related changes $\left(R^{2}=0.091 ; R^{2}\right.$ corr $=0.052$; $F=2.32, \mathrm{df}=3 / 73, P=0.083)$ with $8.0 \%$ explained by "educational level" $(P=0.016)$.

\subsection{Teachers' Appraisals of Their Taiji Courses}

3.3.1. Qualitative Analyses. A total of 816 general appraisals (mean $=6.00 \pm 2.76)$ were stated by the Taiji teachers in their answers to the initial question assessing potential benefits a Taiji-beginners course may offer to newbies. As shown in Figure $1,76 \%$ of all appraisals belonged to the main categories of body-related (43\%) and mind-related appraisals (33\%), while the less frequently mentioned appraisals were captured by the remaining four main categories mind-body-related (17\%), daily-life-related (4\%), knowledge-related (2\%), and process- and context-related appraisals (1\%).

Analyzing frequencies of appraisals in the subcategories, results revealed that $60 \%$ of all Taiji teachers mentioned an "increase of internal balance and peace of mind" as a benefit Taiji-beginners may expect from regular Taiji practice. Other frequently mentioned benefits were "improvement of body awareness" (46\%) and "improvement of physical functioning" (44\%) such as breathing, circulation, blood pressure, immune system, digestion and sleep, "improvement of balance" (38\%), "improvement of motor coordination" (37\%), "increase of power of concentration" (32\%), and "increase of flexibility" (32\%). For complete results see Table 2.

3.3.2. Quantitative Analyses. Taiji teachers appraised a moderate-to-high improvement of stress management in beginners as a result of regular Taiji practice (mean $54.36 \pm$ 
TABLE 1: Socio-demographic data of study participants.

\begin{tabular}{lrr}
\hline & Beginners $(n=74)$ & $50.01 \pm 8.46 ; 29-71$ \\
\hline Age in years (mean \pm SD; range) & $35.35 \pm 7.49 ; 22-50$ & 49 \\
Gender & 30 & 51 \\
Male (\%) & 70 \\
$\quad$ Female (\%) & \\
Education level & 77 \\
$\quad$ With high school degree (i.e., Swiss Matura) (\%) & 23 \\
$\quad$ Without high school degree (\%) & \\
Occupation status & 11 \\
$\quad$ Student (\%) & 89 \\
$\quad$ Full- or part-time job (\%) & 0 \\
Taiji practice in years (mean \pm SD; range) & 0 & 100 \\
Taiji teaching practice in years (mean \pm SD; range) & & $18.60 \pm 8.26 ; 3-46$ \\
\hline
\end{tabular}

SD: standard deviation.

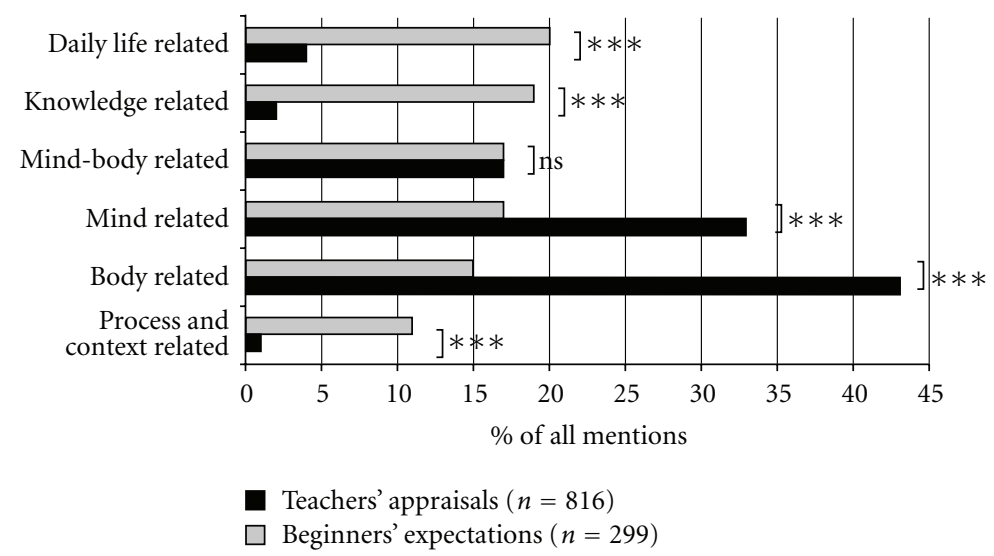

FIGURE 1: Comparison of aggregated beginners' expectations and teachers' appraisals; ns = not significant; ${ }^{* * *}=P<0.001$.

9.67; range $=12$ to 72 ). As revealed in regression analysis, appraisal of a higher improvement of successful stress management in beginners was significantly predicted by lower teaching experience $(\beta=-0.22 ; P=0.024$; see Table 3$)$. The overall explanation of variance by our model is small $\left(R^{2}=0.075 ; R^{2}\right.$ corr $=0.053 ; \mathrm{F}=3.46$, $\mathrm{df}=3 / 13$, $P=0.018)$ with "teaching experience" alone explaining $3.7 \%$ $(P=0.024)$.

3.4. Explorative Comparison of Beginners' Expectations with Teachers' Appraisals. The comparison of the main categories of beginners' expectations and teachers' appraisals is depicted in Figure 1. In contrast to the Taiji teachers, beginners generally stated significantly fewer expectations $(t=6.14 ; \mathrm{df}=200, P<0.001)$. They addressed significantly more frequently daily-life-related $\left(\chi^{2}=73.48 ; P<0.001\right)$ and knowledge-related expectations $\left(\chi^{2}=104.61 ; P<\right.$ $0.001)$ toward their upcoming Taiji course. Taiji teachers in turn were more frequently emphasizing body-related $\left(\chi^{2}=\right.$ 74.72; $P<0.001)$ and mind-related benefits $\left(\chi^{2}=27.06\right.$; $P<0.001)$ a Taiji-beginners course may offer. No group differences were observed for mind-body-related statements $(P=1.00)$. Process- and context-related statements were the least mentioned ones in both groups, yet significantly more often mentioned by Taiji-beginners $\left(\chi^{2}=62.48 ; P<0.001\right)$. Both groups did not differ regarding their ratings related to expected, respectively, appraised Taiji-induced changes in overall stress management $(P=0.54)$.

\section{Discussion}

Our study is the first to examine beginners' expectations and teachers' appraisals towards Taiji-beginners courses. In the following, we will summarize, discuss, and compare our findings of our two surveys.

While both beginners and teachers expressed comparable mind-body-related expectations and appraisals, we found significant differences in daily-life-, knowledge-, mind- and body-related statements. Taiji-beginners expected to learn a new approach that is particularly helpful to foster peace of mind and to improve their stress management. They explicitly emphasized the transferability of course contents into their daily life. In contrast to Taiji-beginners, only a few teachers mentioned knowledge-related and daily-life-related benefits, but many of them stated mind- and body-related benefits of Taiji practice. It might be that Taiji teachers are 
TABLe 2: Frequency of mentioned beginners' expectations and teachers' appraisals of the benefits of a Taiji-beginners course.

\begin{tabular}{|c|c|c|}
\hline Mentioned expectations/appraisals & Beginners $(n=74)$ results in $\%^{1}$ & Teachers $(n=136)$ results in $\%^{1}$ \\
\hline \multicolumn{3}{|l|}{ Daily-life-related expectations/appraisals } \\
\hline Improvement of stress management & 41 & 13 \\
\hline Transferability of course content into daily life & 27 & 9 \\
\hline Counterbalance to daily work & 14 & 3 \\
\hline \multicolumn{3}{|l|}{ Knowledge-related expectations/appraisals } \\
\hline Get to know Taiji in general & 57 & 2 \\
\hline Learning the motion sequences & 15 & 4 \\
\hline Get to know the philosophical background & 5 & 2 \\
\hline Improvement of self-defense & 1 & 1 \\
\hline \multicolumn{3}{|l|}{ Mind-body-related expectations/appraisals } \\
\hline Increase of body awareness & 27 & 46 \\
\hline Increase of relaxation & 26 & 29 \\
\hline Holistic health promotion & 16 & 19 \\
\hline Perception of the flow of Qi/energy & 1 & 8 \\
\hline \multicolumn{3}{|l|}{ Mind-related expectations/appraisals } \\
\hline Increase of internal balance and peace of mind & 32 & 60 \\
\hline Increase of power of concentration & 14 & 32 \\
\hline Expansion of consciousness & 5 & 6 \\
\hline Fostering of self-compassion & 5 & 7 \\
\hline Fostering of equanimity & 4 & 16 \\
\hline Increase of contentedness & 3 & 16 \\
\hline Fostering of mindfulness & 3 & 5 \\
\hline Increase of mental flexibility/openness & 1 & 11 \\
\hline Increase of self-efficacy & 1 & 5 \\
\hline Increase of patience and tenacity & 1 & 1 \\
\hline Increase of self-esteem & 0 & 10 \\
\hline Fostering of compassion and tolerance towards others & 0 & 8 \\
\hline Increase of mental alertness & 0 & 18 \\
\hline Improvement of memory & 0 & 2 \\
\hline \multicolumn{3}{|l|}{ Body-related expectations/appraisals } \\
\hline Be physically active & 16 & 3 \\
\hline Increase of physical well-being & 14 & 16 \\
\hline Strengthening of the body & 8 & 21 \\
\hline Improvement of motor coordination & 7 & 37 \\
\hline Increase of flexibility & 5 & 32 \\
\hline Improvement of balance & 4 & 38 \\
\hline Improvement of body alignment/posture & 3 & 21 \\
\hline Improvement of physical functioning & 3 & 44 \\
\hline Alleviation of physical ailments & 1 & 23 \\
\hline Increase of postural stability & 0 & 16 \\
\hline Increase of looseness & 0 & 4 \\
\hline Reduction of risk of falls & 0 & 1 \\
\hline \multicolumn{3}{|l|}{ Process- and context-related expectations/appraisals } \\
\hline Enjoyment of practicing Taiji & 12 & 5 \\
\hline Meeting new people & 9 & 2 \\
\hline Professional instruction & 9 & 0 \\
\hline Experience of learning progress & 7 & 1 \\
\hline Pleasant course ambience & 5 & 1 \\
\hline
\end{tabular}

${ }^{1} \%$ values refer to the percentage of subjects in each study group. 
TAble 3: Hierarchical regression analyses for (a) Taiji-beginners' expectations related to stress management and (b) for Taiji-teachers' appraisals related to stress management.

\begin{tabular}{|c|c|c|c|c|}
\hline Variables entered & Standardized $\beta$-coefficient & $t$ & $P$ value & $R^{2}$ change \\
\hline \multicolumn{5}{|c|}{ (a) Stress management $(n=74)$} \\
\hline Age & -0.16 & -1.39 & 0.17 & 0.009 \\
\hline Gender & -0.08 & -0.68 & 0.50 & 0.001 \\
\hline Education level* & -0.29 & -2.48 & 0.016 & 0.080 \\
\hline \multicolumn{5}{|c|}{ (b) Stress management $(n=133)$} \\
\hline $\operatorname{Age}^{\circ}$ & 0.17 & 1.83 & 0.07 & 0.010 \\
\hline Gender $^{\circ}$ & 0.14 & 1.68 & 0.10 & 0.027 \\
\hline Teaching experience* & -0.22 & -2.28 & 0.024 & 0.037 \\
\hline
\end{tabular}

${ }^{\circ} P \leq 0.10 ;{ }^{*} P \leq 0.05$.

mainly aiming to transmit implicit procedural rather than explicit declarative knowledge about Taiji to their students. As the retention of procedural knowledge is thought to be longer lasting [41], teachers might have implicitly assumed that the skills their students acquire during their Taiji training would have an impact on their daily life. On the other hand it should be kept in mind that the beginners under study took part in a research project that examined whether Taiji training-related to psychosocial stress reactivity [22]. This participation might have contributed to a frequent mentioning of improvement of stress management among beginners' daily-life-related expectations. However, since stress-management-related benefits of Taiji practice are commonly described in basic literature for Taiji-beginners [7, 42, 43], these expectations might also occur in subjects attending Taiji-beginners classes in naturalistic settings. A possible reason explaining why beginners did not mention body- and mind-related expectations as frequently as teachers did might be the lack of knowledge about these potential effects of Taiji practice. This reasoning is in line with the high frequency of knowledge related expectations in Taiji-beginners. Also to be taken into account is the young to middle age and the good health status of the beginners under study. While older people with an impaired physical condition are likely to expect more body-related benefits when engaging into physical activity programs [44] this might not have been the case for our study group.

Only a few beginners and even fewer teachers mentioned process- and context-related expectations and appraisals. This finding suggests that the vast majority of our study participants are not aware of the potential relevance of process- and context-related factors for treatment outcome [45-48]. It may be that Taiji teachers take the agreeableness and the appropriateness of their teaching methods employed in their courses for granted and therefore rarely mention context and process related aspects of their work. For Taijibeginners, it is very unlikely that they are already familiar with the special role of a Taiji-teacher in terms of being not only teacher but also motivator, coach and therapist [6] as they never experienced a Taiji-lesson before.

Congruence of both study groups was observed in terms of moderate to high expected and appraised improvements in stress management in response to regular Taiji practice.
Our quantitative data shows that a lower educational level predicted higher stress-management-related expectations in Taiji-beginners. This might be due to the fact that people with a less favorable educational background are affected more strongly by the presence of various stressors and absence of multiple resources [49] and therefore are more likely to express higher stress-management-related expectations. Personal resource factors such as mindfulness and selfcompassion are regarded as stress protective trait characteristics $[50,51]$. Therefore, it may be speculated, that subjects with low scores in these two variables have a higher need for improvements in stress management and that this need influences stress-management-related expectations. Notably, in this study we have also assessed self-reported mindfulness and self-compassion scores in all study participants at baseline examination [52]. Indeed, our explorative analysis revealed that there are significant negative correlations of the sum score of stress-management-related expectations with self-reported self-compassion total score $(r=-0.27$; $P=0.019)$, self-compassion subscales "isolation" $(r=$ $0.34 ; P=0.003)$, and "overidentification" $(r=0.30 ; P=$ $0.011)$ but not with mindfulness $(r=-0.17 ; P=0.15)$. Hence, our data partially support a potential association between lower levels of personal resource factors and a higher level of stress-management-related expectations. For the Taiji teachers interestingly, a shorter teaching experience predicted more optimistic teachers' appraisals regarding improvement in stress management. As more experienced teachers are believed to have larger teaching experience with advanced Taiji students, they therefore might perceive beneficial effects in long-term Taiji-practitioners as more pronounced than in beginners. Hence, our finding might be explained by a broader frame of reference employed by the more experienced Taiji teachers.

Our study results provide information with practical relevance. Considering the self-confirming nature of expected treatment responses [25-28], our data suggest that Taiji-beginners are likely to foster mental well-being and enhance stress management by implementing their acquired Taiji-related knowledge and skills in their everyday lives. In fact, we have observed decreased psychobiological reactivity to psychosocial stress [22] and enhanced levels of mindfulness and self-compassion [52] in subjects in 
the Taiji group compared to subjects in the waiting-list control group. However, as explorative analyses revealed, these effects have not been found to be directly modulated by stress-management related expectancies (data not shown). Potential synergistic effects of beginners' expectations with other treatment components such as teacher's appraisals on treatment outcomes should be subject of future research. Since beginners' expectations and teachers' appraisals differ in several points, we recommend Taiji teachers to proactively ask their new students about their course expectations and to inform them about potential benefits of regular Taiji practice early in the course. This can prevent students from disappointment due to clinging to inadequate expectancies and helps them to modify their expectations towards greater congruence with teachers' appraisals of potential benefits a Taiji beginner course may offer. Also teachers might adapt their courses to respond to their students' needs more effectively. Such congruence in turn would be likely to enhance the working alliance and to increase beginners' course satisfaction and course adherence. Despite this reasoning being highly plausible, our data do not allow to draw any conclusion about the impact of the observed incongruence between beginners' expectations and teachers' appraisals on the outcomes of the Taiji courses or the beginners' and/or teachers' course satisfaction. Still our findings may provide information of practical relevance: Since Taiji is not commonly practiced among health care professionals [53], our data collected from 136 Taiji teachers provides valuable insights into potential benefits of Taiji-beginners courses that might be helpful for health care professionals for their own as well as for their patients' information.

The following limitations need to be addressed. First, Taiji-beginners were not students of the investigated teachers; thus we were not able to assess the degree of working alliance between both study groups. For the same reason a potential negative influence of the mismatch between beginners' expectations and teachers' appraisals on courserelated outcome values could not have been investigated. Secondly, the results of Taiji-beginners' expectations are restricted to healthy young to middle-aged and predominantly well-educated participants. People with functional limitations should be included in future studies, as this population is regarded to represent a large proportion of all Taiji practitioners [54]. Third, because our survey of Taijibeginners was nested within a trial examining effects of Taiji on psychobiological stress reactivity, this circumstance might have influenced stress-management-related expectations of our Taiji novices. Therefore, we recommend for future studies in this field to investigate Taiji-beginners and their corresponding teachers under naturalistic conditions.

In addition to the above-mentioned practical implications of our findings, the main strengths of this study are the consideration and comparison of both beginners' expectations as well as teachers' appraisals, the combination of qualitative and quantitative data assessment, which allows us to provide an overview of general as well as more specifically stress-management-related expectations and appraisals. Moreover, a relatively large population of active Taiji teachers has participated in our survey.

\section{Conclusion}

The results of our study increase the awareness of and knowledge about the nature of expectancies and appraisals in Taiji-beginners practice. We have found that educational background, the level of self-compassion, and teaching experience are involved in shaping stress-managementrelated expectations and appraisals. The impact of students' expectations, teachers' appraisals, and the interaction of both on treatment outcomes of Taiji interventions remains to be further investigated.

\section{Appendix}

\section{Questionnaire Assessing Expected/Perceived Changes in Stress Management Attributed to Taiji Practice}

Please indicate to which degree the below mentioned statements match your personal opinion: $1=$ strongly disagree; 2 = disagree; $3=$ rather disagree; $4=$ rather agree; 5 = agree; 6 $=$ strongly agree.

(i) Items answered by Taiji-beginners: From regular Taiji practice, ${ }^{*}$ I do expect that I can...

(ii) Items answered by Taiji teachers: A beginner who is regularly practicing Taiji* can expect that he/she can...

(1) deal with stressful situations in a more relaxed manner;

(2) be more self-aware in difficult situations;

(3) increase my, resp., his/her feeling of physical fitness;

(4) better perceive the needs of my, resp., his/her body;

(5) generally feel more calm and balanced;

(6) be more mindful in daily life;

(7) feel less troubled by unexpected inconveniences;

(8) rely more on my, resp., his/her inner strengths when facing unexpected inconveniences;

(9) maintain calmness in challenging situations;

(10) recover more rapidly after a demanding task;

(11) increase my, resp., his/her power of concentration;

(12) socialize more with others.

* Regular class attendance twice a week during three months including independent Taiji practice at home.

\section{Acknowledgments}

The authors acknowledge the financial support of Stiftung für Komplementärmedizin, Gottfried und Julia BangerterRhyner Stiftung and Parrotia Stiftung (to M. Nedeljkovic and B. Ausfeld-Hafter), and of the Swiss National Foundation 
Grant to PP00P1_128565/1 (to P. H. Wirtz). The funding sources had no role in study design, in the collection, analysis and interpretation of data, in the writing of the paper, and in the decision to submit the paper for publication. Further, the authors would like to thank Ms. Isabelle Pfaff for her skillful assistance in conducting the online survey and Mr. Dominikus Vogl for his helpful advice in statistical analyses.

\section{References}

[1] M. B. Ospina, K. Bond, M. Karkhaneh et al., "Clinical trials of meditation practices in health care: characteristics and quality," Journal of Alternative and Complementary Medicine, vol. 14, no. 10, pp. 1199-1213, 2008.

[2] A. Michalsen, "Stressed patients, stressed physicians and the need for mind-body medicine," Forschende Komplementarmedizin, vol. 17, no. 5, pp. 237-239, 2010.

[3] A. Chiesa and A. Serretti, "Mindfulness-based stress reduction for stress management in healthy people: a review and metaanalysis," Journal of Alternative and Complementary Medicine, vol. 15, no. 5, pp. 593-600, 2009.

[4] P. Grossman, L. Niemann, S. Schmidt, and H. Walach, "Mindfulness-based stress reduction and health benefits: a meta-analysis," Journal of Psychosomatic Research, vol. 57, no. 1, pp. 35-43, 2004.

[5] P. M. Wolsko, D. M. Eisenberg, R. B. Davis, and R. S. Phillips, "Use of mind-body medical therapies: results of a national survey," Journal of General Internal Medicine, vol. 19, no. 1, pp. 43-50, 2004.

[6] P. M. Wayne and T. J. Kaptchuk, "Challenges inherent to T'ai Chi research: part I-T'ai Chi as a complex multicomponent intervention," Journal of Alternative and Complementary Medicine, vol. 14, no. 1, pp. 95-102, 2008.

[7] R. Robinson, Tai Chi For You-The Comprehensive Guide to Tai Chi at Home for Everybody, Duncan Baird, London, UK, 2006.

[8] P. M. Barnes, E. Powell-Griner, K. McFann, and R. L. Nahin, "Complementary and alternative medicine use among adults: United States, 2002," Advance Data, no. 343, pp. 1-19, 2004.

[9] P. J. Klein and W. D. Adams, "Comprehensive therapeutic benefits of Taiji: a critical review," American Journal of Physical Medicine and Rehabilitation, vol. 83, no. 9, pp. 735-745, 2004.

[10] M. S. Lee and E. Ernst, "Systematic reviews of T'ai Chi: an overview," British Journal of Sports Medicine, vol. 46, no. 10, pp. 713-718, 2012.

[11] S. L. Wolf, H. X. Barnhart, N. G. Kutner, E. McNeely, C. Coogler, and $\mathrm{T}$. $\mathrm{Xu}$, "Reducing frailty and falls in older persons: an investigation of Tai Chi and computerized balance training," Journal of the American Geriatrics Society, vol. 44, no. 5, pp. 489-497, 1996.

[12] A. Voukelatos, R. G. Cumming, S. R. Lord, and C. Rissel, "A randomized, controlled trial of tai chi for the prevention of falls: the central sydney Tai Chi trial," Journal of the American Geriatrics Society, vol. 55, no. 8, pp. 1185-1191, 2007.

[13] A. W. K. Chan, A. Lee, L. K. P. Suen, and W. W. S. Tam, “Tai chi Qigong improves lung functions and activity tolerance in COPD clients: a single blind, randomized controlled trial," Complementary Therapies in Medicine, vol. 19, no. 1, pp. 3-11, 2011.

[14] C. Wang, C. H. Schmid, R. Rones et al., "A randomized trial of tai chi for fibromyalgia," New England Journal of Medicine, vol. 363 , no. 8, pp. 743-754, 2010.
[15] W. Zhu, S. Guan, and Y. Yang, "Clinical implications of Tai Chi interventions: a review," American Journal of Lifestyle Medicine, vol. 4, no. 5, pp. 418-432, 2010.

[16] C. Wang, "Tai Chi and rheumatic diseases," Rheumatic Disease Clinics of North America, vol. 37, no. 1, pp. 19-32, 2011.

[17] C. Wang, R. Bannuru, J. Ramel, B. Kupelnick, T. Scott, and C. H. Schmid, "Tai Chi on psychological well-being: systematic review and meta-analysis," BMC Complementary and Alternative Medicine, vol. 10, article 23, 2010.

[18] R. E. Taylor-Piliae, W. L. Haskell, C. M. Waters, and E. S. Froelicher, "Change in perceived psychosocial status following a 12-week Tai Chi exercise programme," Journal of Advanced Nursing, vol. 54, no. 3, pp. 313-329, 2006.

[19] L. Zhang, C. Layne, T. Lowder, and J. Liu, "A review focused on the psychological effectiveness of Tai Chi on different populations," Evidence-Based Complementary and Alternative Medicine, vol. 2012, Article ID 678107, 9 pages, 2012.

[20] T. Esch, J. Duckstein, J. Welke, G. B. Stefano, and V. Braun, "Mind/body techniques for physiological and psychological stress reduction: stress management via Tai Chi traininga pilot study," Medical Science Monitor, vol. 13, no. 11, pp. CR488-CR497, 2007.

[21] J. L. W. Robins, N. L. McCain, D. P. Gray, R. K. Elswick, J. M. Walter, and E. McDade, "Research on psychoneuroimmunology: Tai chi as a stress management approach for individuals with HIV disease," Applied Nursing Research, vol. 19, no. 1, pp. 2-9, 2006.

[22] M. Nedeljkovic, B. Ausfeld-Hafter, K. Streitberger, R. Seiler, and P. Wirtz, "Taiji practice attenuates psychobiological stress reactivity - a randomized controlled trial in healthy subjects," Psychoneuroendocrinology, vol. 37, pp. 1171-1180, 2012.

[23] S. Gatts, "Neural mechanisms underlying balance control in Tai Chi," Medicine and Sport Science, vol. 52, pp. 87-103, 2008.

[24] B. Iuliano, D. Grahn, V. Cao, B. Zhao, and J. Rose, "Physiologic correlates of T'ai Chi Chuan," Journal of Alternative and Complementary Medicine, vol. 17, no. 1, pp. 77-81, 2011.

[25] I. Kirsch, "Specifying nonspecifics: psychological mechanisms of placebo effects," in The Placebo Effect: An Interdisciplinary Exploration, A. Harrington, Ed., pp. 166-186, Harvard University Press, Cambridge, Mass, USA, 1997.

[26] M. V. Mondloch, D. C. Cole, and J. W. Frank, "Does how you do depend on how you think you'll do? A systematic review of the evidence for a relation between patients' recovery expectations and health outcomes," Canadian Medical Association Journal, vol. 165, no. 2, pp. 174-179, 2001.

[27] J. Pariente, P. White, R. S. J. Frackowiak, and G. Lewith, "Expectancy and belief modulate the neuronal substrates of pain treated by acupuncture," NeuroImage, vol. 25, no. 4, pp. 1161-1167, 2005.

[28] K. Linde, C. M. Witt, A. Streng et al., "The impact of patient expectations on outcomes in four randomized controlled trials of acupuncture in patients with chronic pain," Pain, vol. 128, no. 3, pp. 264-271, 2007.

[29] D. W. So, "Acupuncture outcomes, expectations, patientprovider relationship, and the placebo effect: implications for health promotion," American Journal of Public Health, vol. 92, no. 10, pp. 1662-1667, 2002.

[30] J. Waylett-Rendall and L. O. Niemeyer, "Exploratory analysis to identify factors impacting return-to-work outcomes in cases of cumulative trauma disorder," Journal of Hand Therapy, vol. 17, no. 1, pp. 50-57, 2004. 
[31] L. A. Learman, J. Avorn, D. E. Everitt, and R. Rosenthal, "Pygmalion in the nursing home: the effects of caregiver expectations on patient outcomes," Journal of the American Geriatrics Society, vol. 38, no. 7, pp. 797-803, 1990.

[32] C. M. Witt, F. Martins, S. N. Willich, and L. Schuetzler, "Can I help you? Physicians' expectations as predictor for treatment outcome," European Journal of Pain, vol. 16, no. 10, pp. 14551466, 2012.

[33] A. M. Hall, P. H. Ferreira, C. G. Maher, J. Latimer, and M. L. Ferreira, "The influence of the therapist-patient relationship on treatment outcome in physical rehabilitation: a systematic review," Physical Therapy, vol. 90, no. 8, pp. 1099-1110, 2010.

[34] A. O. Horvath and B. D. Symonds, "Relation between working alliance and outcome in psychotherapy: a meta-analysis," Journal of Counseling Psychology, vol. 38, no. 2, pp. 139-149, 1991.

[35] A. S. Joyce and W. E. Piper, "Expectancy, the therapeutic alliance, and treatment outcome in short- term individual psychotherapy," Journal of Psychotherapy Practice and Research, vol. 7, no. 3, pp. 236-248, 1998.

[36] F. Al-Darmaki and D. M. Kivlighan, "Congruence in clientcounselor expectations for relationship and the working alliance," Journal of Counseling Psychology, vol. 40, no. 4, pp. 379-384, 1993.

[37] P. Jin, "Efficacy of Tai Chi, brisk walking, meditation, and reading in reducing mental and emotional stress," Journal of Psychosomatic Research, vol. 36, no. 4, pp. 361-370, 1992.

[38] S. D. Klein, "Why Patients choose acupuncture or qigong, and what they expect from the treatment," Deutsche Zeitschrift fur Akupunktur, vol. 52, no. 4, pp. 18-23, 2009.

[39] R. B. Catell, "The scree test for the number of factors," Multivariate Behavioral Research, vol. 1, pp. 245-276, 1966.

[40] P. Mayring, An Introduction Into Qualitative Research in Social Sciences, Beltz, Weinheim, Germany, 2002.

[41] N. Pennington and B. Rehder, "Looking for transfer and interference," in Psychology of Learning and Motivation: Advances in Research and Theory, D. L. Medin, Ed., pp. 223-289, Academic Press, San Diego, Calif, USA, 1995.

[42] M. Rasinaho, M. Hirvensalo, R. Leinonen, T. Lintunen, and T. Rantanen, "Motives for and barriers to physical activity among older adults with mobility limitations," Journal of Aging and Physical Activity, vol. 15, no. 1, pp. 90-102, 2007.

[43] K. C. Lam, Step-by-Step Tai Chi, Touchstone Books, New York, NY, USA, 1994.

[44] B. Frantzis, Tai Chi: Health for Life, Blue Snake Books, Berkley, Calif, USA, 2006.

[45] M. Schweitzer, L. Gilpin, and S. Frampton, "Healing spaces: elements of environmental design that make an impact on health," Journal of Alternative and Complementary Medicine, vol. 10, supplement 1, pp. S-71-S-83, 2004.

[46] H. MacPherson, L. Thorpe, and K. Thomas, "Beyond needling - therapeutic processes in acupuncture care: a qualitative study nested within a low-back pain trial," Journal of Alternative and Complementary Medicine, vol. 12, no. 9, pp. 873-880, 2006.

[47] W. B. Jonas and R. A. Chez, "Toward optimal healing environments in health care," Journal of Alternative and Complementary Medicine, vol. 10, supplement 1, pp. S-1-S-6, 2004.

[48] Z. Di Blasi, E. Harkness, E. Ernst, A. Georgiou, and J. Kleijnen, "Influence of context effects on health outcomes: a systematic review," The Lancet, vol. 357, no. 9258, pp. 757-762, 2001.
[49] B. Mulder, M. de Bruin, H. Schreurs, E. van Ameijden, and C. van Woerkum, "Stressors and resources mediate the association of socioeconomic position with health behaviours," BMC Public Health, vol. 11, no. 1, article 798, 2011.

[50] K. W. Brown and R. M. Ryan, "The benefits of being present: mindfulness and its role in psychological well-being," Journal of Personality and Social Psychology, vol. 84, no. 4, pp. 822-848, 2003.

[51] A. B. Allen and M. R. Leary, "Self-compassion, stress, and coping," Social and Personality Psychology Compass, vol. 4, no. 2, pp. 107-118, 2010.

[52] M. Nedeljkovic, P. H. Wirtz, and B. Ausfeld-Hafter, "Effects of Taiji practice on mindfulness and self-compassion in healthy participants_a randomized controlled trial," Mindfulness, vol. 3, no. 3, pp. 200-208, 2012.

[53] A. Burke, K. Ginzburg, K. Collie, D. Trachtenberg, and M. Muhammad, "Exploring the role of complementary and alternative medicine in public health practice and training," Journal of Alternative and Complementary Medicine, vol. 11, no. 5, pp. 931-936, 2005.

[54] C. A. Okoro, G. Zhao, C. Li, and L. S. Balluz, "Use of complementary and alternative medicine among USA adults with functional limitations: for treatment or general use?" Complementary Therapies in Medicine, vol. 19, no. 4, pp. 208215, 2011. 


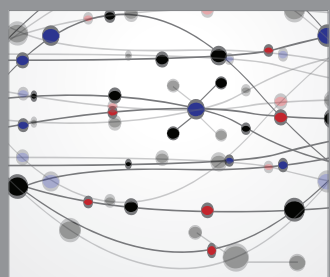

The Scientific World Journal
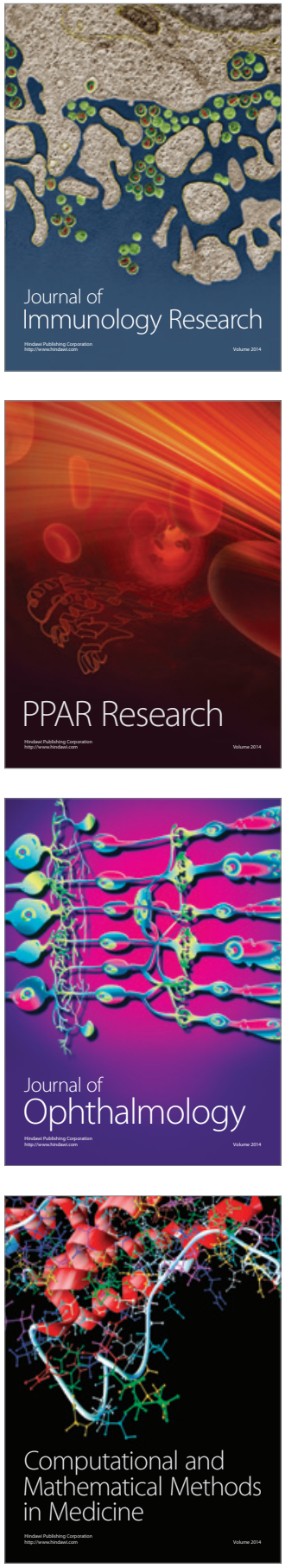

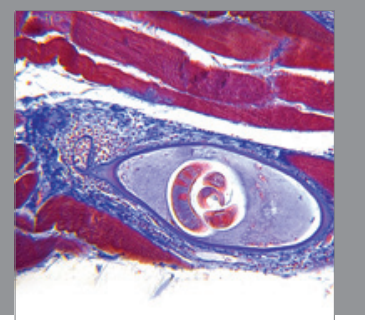

Gastroenterology

Research and Practice
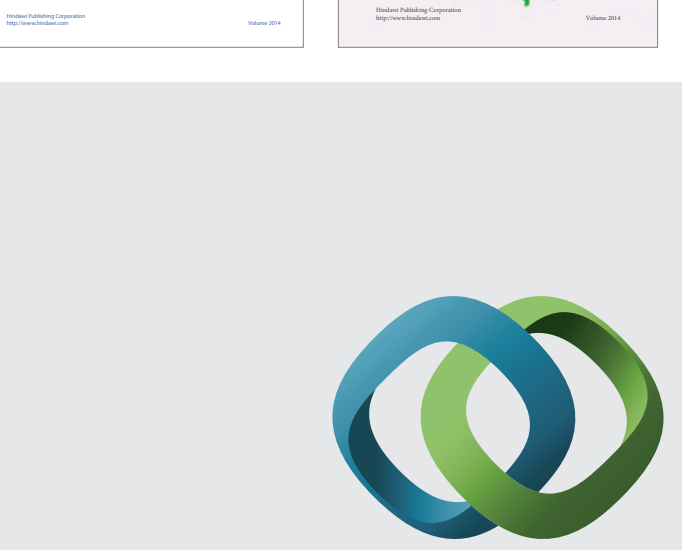

\section{Hindawi}

Submit your manuscripts at

http://www.hindawi.com
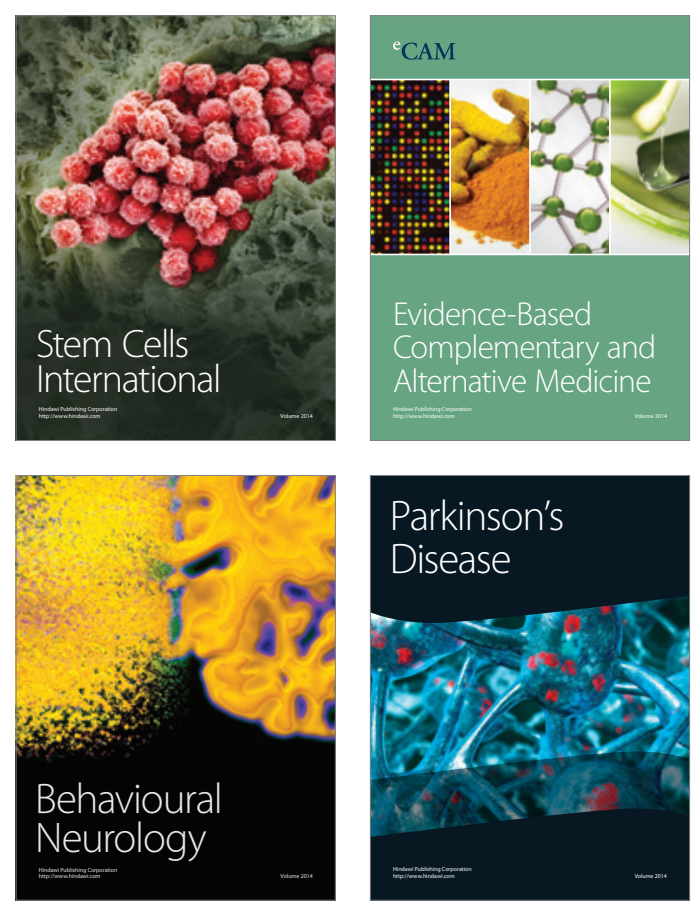

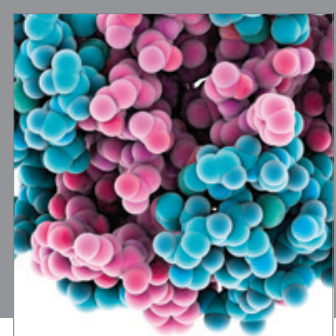

Journal of
Diabetes Research

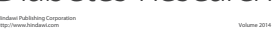

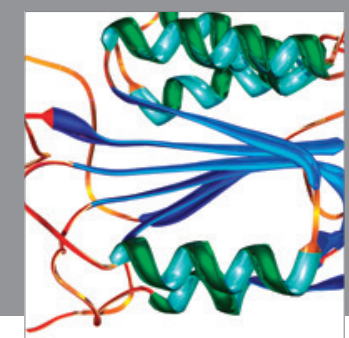

Disease Markers
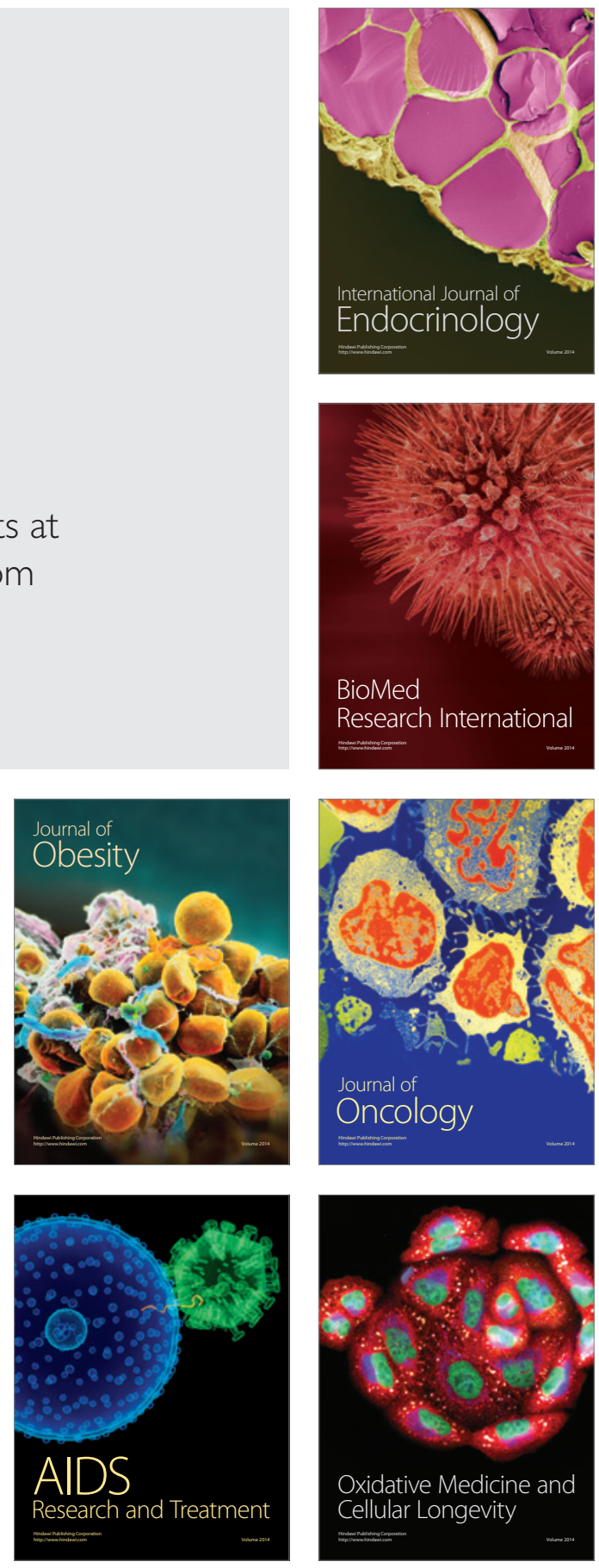